\title{
Publisher Correction: Large inequality in international and intranational energy footprints between income groups and across consumption categories
}

Yannick Oswald (iD, Anne Owen (iD) and Julia K. Steinberger (iD

Correction to: Nature Energy https://doi.org/10.1038/s41560-020-0579-8, published online 16 March 2020.

In the version of this Article originally published, in the sentence beginning "Oxfam added ${ }^{2}$ that...", the value " $2 \%$ " should have been " $82 \%$ ". This has now been corrected. In addition, in the provided Source Data file for Fig. 2, the values in the 'Gtap 9 ID' column were incorrect; this file has now been replaced.

Published online: 30 March 2020

https://doi.org/10.1038/s41560-020-0606-9

(c) The Author(s), under exclusive licence to Springer Nature Limited 2020 